\title{
Expressividade na opinião de cantores líricos
}

\author{
Enio Lopes Mello (PUC, São Paulo, SP) \\ enio.mello@superig.com.br
}

Léslie Piccolotto Ferreira (PUC, São Paulo, SP)

lesliepf@pucsp.com

Natália Fonseca Pacheco (PUC, São Paulo, SP)

nfpacheco@gmail.com

Marta Assumpção de Andrada e Silva (PUC, São Paulo, SP)

m.andradaesilva@gmail.com

Resumo: Investigação sobre a opinião de cantores líricos em relação à expressividade na performance operística. Método: 50 cantores líricos (24 mulheres e 26 homens) citaram cinco palavras relacionadas à expressividade do cantor de ópera. Resultados: a partir da frequência das repetições de palavras nas respostas dos cantores foram elaborados seis eixos temáticos: emoção (76\%); técnica (64\%); habilidades (58\%); entrega (54\%); corpo (48\%) e interpretação (38\%) que foram correlacionados aos dados de caracterização dos sujeitos. Conclusão: a partir dos resultados desta pesquisa podese inferir que a expressividade do cantor lírico diz respeito à emoção, à técnica e à habilidade do cantor de se entregar ao personagem e ao público, e isso se conquista com anos de experiência na profissão.

Palavras chaves: expressividade no canto e na atuação; canto em ópera.

\section{Expressiveness in the opinion of classical singers}

Abstract: Investigation about the opinion of classical singers in relation to expressiveness in opera performance. Method: 50 classical singers ( 24 females and 26 males) provided five words related to the expressiveness of opera singers. Results: The following six themes were defined from the frequency of word repetition in the singers' answers: emotion (76\%); technique (64\%); skills (58\%); involvement (54\%); body (48\%) and interpretation (38\%). These were crossed with the subjects' characterization data. Conclusion: The data suggest that the expressiveness of classical singers is related to emotion, technique, and the ability of the singer to completely involve himself with the character and audience, and this is achieved with years of experience in the profession.

Keywords: expressiveness in singing and acting; opera singing.

\section{1- Introdução}

Expressividade é um tema que provoca muita controvérsia, porque além de ser subjetivo, depende da linha de pressupostos teóricos que se adota. Na linha da Comunicação, por exemplo, tudo é expressivo, não obstante ao julgo de valor, ou seja, se é bom ou ruim, sempre haverá uma expressão que comunica algo, sem conotações de comunicação positiva ou negativa.

Entretanto, apesar da inegável relevância do tema, existem poucas pesquisas na área da música que abordem a expressividade com consenso de raciocínio.
Neste sentido, CAVAZOTTI (2001) afirmou que, apesar da produção de pesquisa na área da música sobre a performance ter crescido consideravelmente nos últimos vinte anos, ainda é grande a dificuldade em se abordar questões centrais, intrínsecas à experiência, tais como as referentes à expressividade e ao significado musical. Cientes da complexidade que envolve esse tema serão expostas a seguir várias conjecturas, concernentes da área da musica, para plausíveis reflexões no canto lírico.

Para MUSZKAT et al (2000), a música é uma linguagem, porque se baseia em um sistema de signos, naturais 
ou convencionados, que transmitem informações ou mensagens de um sistema a outro, seja, orgânico, social ou cultural. Para o autor, há um paralelo entre a linguagem verbal e a musical, pois ambas utilizam-se de estruturas sensoriais para recepção e processamento auditivo (fonemas, sons) e visual (grafemas da leitura verbal e musical), que dependem da integridade funcional das regiões envolvidas com atenção, memória e na utilização das estruturas eferentes motoras, necessárias tanto para a fala, quanto para a execução musical. No entanto, o código utilizado na música não separa significante e significado, diferentemente da linguagem verbal, ou seja, a mensagem da música não se condiciona à convenção semântico-linguística, mas a uma organização que transmite ideias, por meio de estruturas significativas, que é a música propriamente dita.

De acordo com SCHENKER (2000), entre a partitura e a execução do intérprete há um espaço em branco a ser preenchido. Nas partituras, as intenções expressivas do compositor, quanto às dinâmicas e timbres, são geralmente indicadas por instruções verbais subjetivas e os valores exatos de duração das notas são grafados na partitura, porém nem sempre são executados. Segundo o autor, isto ocorre porque a notação musical não pode dar conta de todas as pequenas nuances da execução de uma obra, pois a escrita musical é racional, cartesiana, enquanto que a obra de arte é viva, orgânica. Portanto, como nem tudo está escrito, cabe ao intérprete devolver à obra sua vitalidade original, ao reconhecer e ser capaz de executar o que não se encontra notado na partitura.

Sobre este assunto, SHIFRES (2001) destacou duas abordagens teóricas: a que valoriza a execução como realização da estrutura musical derivada da análise sistemática da obra e a que valoriza a execução, como a realização das normas estilísticas que definem a prática comum da execução de uma época. Contudo, julgamentos acerca da autenticidade da execução provenientes de quaisquer dos dois enfoques correm 0 risco de serem omissos quanto à ação criativa peculiar do executante. Neste caso, a história da execução musical revela que a liberdade interpretativa é vista como força contrária, tanto à vertente do marco estilístico, quanto à da unidade da obra. Pelo exposto, o autor considerou que o problema da autenticidade da interpretação não está restrito às questões da aplicação das normas estilísticas ou das gramáticas interpretativas, mas abrange outra dimensão. Desse modo, mesmo que se possa considerar uma interpretação mais pertinente que outra, não é razoável falar de fidelidade ou autenticidade. Toda obra musical tem na sua estrutura significados sociais e culturais, que o intérprete assimila ou rechaça, conforme a visão musical e representações da obra, do compositor, da época e também do mundo que o cerca.

HIGUCHI e LEITE (2007) e HIGUCHI (2008) refletiram acerca das questões que transitam entre o espaço da fidelidade ao texto e a liberdade do intérprete, em pesquisas de análises descritivas interdisciplinares desenvolvidas nos campos da Musicologia, Ensino Musical, Psicologia e na Neurociência, cujo objetivo é explicar ou dar sentido às polêmicas relacionadas às funções do rigor métrico e da fidelidade ao texto na expressividade interpretativa musical. As autoras consideram que as indicações da partitura podem ser um elemento propulsor no desenvolvimento de uma capacidade expressiva mais elaborada.

Para PAULA e BORGES (2004), a performance musical precisa ser elaborada e construída. 0 fazer musical possui um caráter interdisciplinar, implicado na intensa conexão com outras áreas de conhecimento. Isso acontece porque as informações contidas no texto musical não são automaticamente processadas para transformarem-se nas ações motoras que irão produzir os sons desejados. Para alcançar esse nível, o intérprete, além de decifrar o texto musical, precisa arquitetar, muitas vezes arduamente, as ações e os sons desejados. As informações contidas no texto musical precisam ser pensadas, elaboradas e processadas, e isto requer tempo e energia. Esse trabalho geralmente é executado pelo intérprete por meio da repetição de movimentos e da escuta. Segundo os autores, um dos pontos críticos da performance está associado à capacidade para se dominar o estresse de palco, ou seja, o controle emocional. De acordo com SAPOLOSKY (2003, p.80), um estressor é algo do ambiente com o poder de tirar o corpo da homeostase (equilíbrio) e o organismo responde ao estresse fazendo uma série de adaptações fisiológicas, a fim de restabelecer o equilíbrio.

A maioria dos autores citados relaciona a expressividade ao sucesso do cantor em comunicar significado, ou seja, conseguir transmitir para o ouvinte, durante a performance o sentido do que canta. Para ANDRADA E SILVA (2005, p.94), o canto expressivo acontece quando o cantor consegue transmitir ao seu público, de modo altamente significativo, com vivacidade, força e energia, as ideias, as emoções e os valores implícitos na música. Baseada nesta afirmação, a autora traça dez princípios que devem nortear a intervenção fonoaudiológica junto ao cantor, e dentre esses se destacam: alimentar o prazer de estar no palco; induzi-lo ao conhecimento do sentido da letra da música; verificar o domínio de técnicas e acima de tudo, convencelo que deve cantar com o coração e com a alma.

Para SALGADO (2001e 2006), as emoções "artísticas" se aproximam ou se assemelham às emoções ditas "reais". Se o cantor interpretar com uma grande convicção interior, o efeito da expressão com que representa cada uma das emoções será mais convincente e, portanto, neste sentido, mais autêntica.

GABRIELSSON e JUSLIN (1996) evidenciaram as relações dos parâmetros acústicos e as intenções expressivas nas performances de nove músicos profissionais. Os músicos receberam instruções para interpretarem segundo os adjetivos: alegre, triste, raivoso, suave, amedrontado, 
solene e inexpressivo. Os resultados mostraram a complexidade da questão diante das inúmeras escolhas possíveis para transmitir as intenções expressivas. Efeitos acústicos similares podem representar motivações expressivas diversas e efeitos acústicos diferentes podem representar as mesmas ideias expressivas. Constataram, por este motivo, as dificuldades presentes na identificação das causas de características perceptivas tão evidentes.

Para COSTA (2009) o trabalho cênico dirigido à formação de jovens cantores pode representar um recurso facilitador na criação e manutenção de uma obra, sejam nos aspectos acústicos vocais ou no domínio de palco quando se estabelecem a formação de um coro cênico, ao mesmo tempo em que desempenha um papel lúdico e prazeroso aos participantes. Neste sentido, LOUREIRO (2006) afirmou que as diferenças de teor expressivo são percebidas com bastante clareza até mesmo por ouvintes leigos. Sendo assim, uma interpretação expressiva, mesmo que contenha algumas imprecisões e erros, é sempre mais apreciada que uma performance tecnicamente perfeita.

Neste sentido ABDO (2005, p.361) comunga com os postulados de PAREYSON (1997, p.120), sobre a "estética da formatividade". Ambos consideram que o centro da autonomia da arte é a própria especificação da forma artística. A primeira autora concebeu por forma artística o acabamento de um processo que tem como máxima expressão de êxito a adequação consigo mesmo e não a algum fim ou valor extrínseco. Segundo ela, o artista exercita sua "formatividade" no ato da criação. Nesse exercício está presente toda a sua vida espiritual. Assim, no "modo de formar" do artista, ou seja, em seu "estilo", que é ao mesmo tempo pessoal e histórico, está presente sua vontade expressiva e comunicativa. Por este motivo, na obra de arte, até mesmo um detalhe mínimo diz, comunica algo. Tudo nela carrega significados, uma vez que está imbuído dos sentimentos, aspirações e convicções do artista.

A partir dos expostos acima, o objetivo do estudo foi investigar a opinião de cantores líricos sobre a expressividade na performance operística.

\section{2- Método}

Este artigo é resultado de uma pesquisa transversal, de caráter descritivo e qualitativo, que foi aprovada pelo comitê de ética em pesquisa da Pontifícia Universidade Católica de São Paulo (PUC/SP), sob o número 119/2008.

\section{1 - Seleção dos sujeitos}

Os critérios para seleção dos sujeitos foram: ter idade mínima 21 anos, sem limite máximo de idade; experiência mínima de três anos como cantor (a) lírico (a) profissional. Participaram desta pesquisa 50 cantores líricos, identificados como S1, S2, S3 e assim sucessivamente até S50.

\section{2- Procedimentos}

Os cantores foram entrevistados via internet (Messenger- webcam e microfone) ou pessoalmente. Após identificação (iniciais do nome, faixa-etária, classificação vocal, tempo de atuação na profissão, formação em canto, exercício de outras profissões), solicitou-se que citassem cinco palavras que na opinião deles estivessem relacionadas à expressividade do cantor lírico. Esta entrevista foi gravada (digital voicerSONY-ICD-P620) e posteriormente transcrita.

\section{3- Análises dos dados}

Os dados de identificação serviram para a caracterização dos sujeitos e as palavras citadas foram submetidas a análise de conteúdo, conforme proposta de MINAYO (2004), que consiste em descobrir os núcleos de sentido que compõem uma comunicação, cuja presença ou frequência signifiquem alguma coisa que esteja ligada ao objetivo proposto. $\mathrm{Na}$ análise de conteúdo, duas abordagens foram possíveis: análise de eixos temáticos (qualitativa) e dedução frequencial (quantitativa). Desta forma, os eixos temáticos foram extraídos da repetição de termos, que foram codificados, divididos e reagrupados por semelhança. Foram categorizados 06 eixos temáticos, a saber: técnica, emoção, corpo, interpretação, entrega e habilidades. Os dados foram transpostos para uma planilha (Microsoft Excel 2010) e em seguida fez-se o cruzamentos das caracterizações dos sujeitos com os eixos temáticos sobre expressividade, descritos anteriormente. Para tanto, utilizou-se 0 teste estatístico de correlação (Pearson) por meio do Data Analysis and Statistical Software (STATA), sendo que, o valor de significância adotado foi de $p \leq 0,05$, ou seja, assumiu-se a probabilidade de apenas 5\% das respostas dos cantores não serem comuns para todos que responderam sobre o mesmo eixo temático, desta forma, quanto menor for o valor de $p$, maior será a concordância de opinião entre os cantores.

\section{3- Resultados}

Os eixos temáticos mais referidos pelos 50 sujeitos da pesquisa foram: "emoção" com 38 citações (76\%); seguido por "técnica" 32 (64\%), "habilidade" 29 (58\%); "entrega" 27 (54\%); "corpo" 40 (48\%) e for fim, "interpretação" 19 (38\%).

A caracterização dos participantes, quanto às variáveis sexo, faixa etária, formação, tempo de docência e classificação vocal está exposta no quadro (Ex.1).

E a correlação entre os eixos temáticos sobre expressividade e a caracterização dos sujeitos segundo sexo, classificação vocal, formação, tempo de atividade e faixa etária está exposta na tabela (Ex.2). 


\begin{tabular}{lcc}
\hline SEXO & $\mathbf{n}$ & $\mathbf{\%}$ \\
\hline Feminino & 24 & 48 \\
Masculino & 26 & 52 \\
\hline & $\mathbf{5 0}$ & $\mathbf{1 0 0}$ \\
\hline FAIXA ETÁRIA & & \\
\hline 20 a 30 & 12 & 24 \\
31 a 40 & 13 & 26 \\
Acima de 41 & 25 & 50 \\
\hline & $\mathbf{5 0}$ & $\mathbf{1 0 0}$ \\
\hline FORMAÇÃO EM MUSICA/CANTO & & \\
\hline Informal & 17 & 34 \\
Graduação & 33 & 66 \\
\hline & $\mathbf{5 0}$ & $\mathbf{1 0 0}$ \\
\hline TEMPO DE DOCÊNCIA EM ANOS & & \\
\hline 03 a 10 & 15 & 30 \\
11 a 20 & 22 & 44 \\
Acima de 21 & 13 & 26 \\
& & \\
\hline CLASSIFICAÇÃO VOCAL & & \\
\hline Sopranos & 18 & 36 \\
Mezzo-sopranos & 06 & 12 \\
Tenores & 05 & 10 \\
Baritonos & 15 & 30 \\
Baixos & 06 & 12 \\
\hline Total de participantes & $\mathbf{5 0}$ & $\mathbf{1 0 0}$ \\
\hline
\end{tabular}

Ex.1 - Caracterização dos sujeitos: número (n) e porcentagem (\%), segundo sexo, faixa etária, formação em música/canto; tempo de docência e classificação vocal.

\section{4- Discussão}

A partir da análise dos dados expostos no Ex. 1, podese observar que houve uma homogeneidade de opinião entre os cantores entrevistados, haja vista que, apenas no cruzamento do "tempo de atividade" com o eixo temático "entrega", houve correlação estatisticamente significante, ou seja, $p \leq 0,05$. Este dado nos permite inferir que quanto maior o tempo de profissão, maior será a entrega do cantor para a atividade a que se propõe, ou seja, há uma diferença entre cantores iniciantes e os mais experientes na profissão, no que diz respeito à entrega do cantor à personagem da ópera, sendo que, cantores mais experientes, com maior tempo de atividade profissional, acreditam que a entrega esteja atrelada à capacidade de se tornar expressivo.

Nota-se também uma tendência de a entrega estar relacionada com a formação do cantor, isto porque, os resultados dessa correlação $(0,057 \%)$ se aproximaram do valor de significância $(p \leq 0,05)$. Pode-se inferir a partir desse dado que, para os cantores graduados em músical canto, a entrega ao personagem é mais relevante do que para aqueles com formação informal. Para PAULA e BORGES (2004), a formação e o estudo são base para a concepção de uma interpretação mais livre e expressiva. Nesta perspectiva, a preparação estará atrelada a capacidade de conjugar áreas interdisciplinares do conhecimento.

Os dados sobre o eixo temático "entrega" vão ao encontro da ideia de doação, que foi abordada por ANDRADA E SILVA (2005, p.95). Segundo a autora, a doação do cantor ao papel interpretado e ao seu público configura uma possibilidade de se tornar expressivo, isto porque ao doarse o cantor estabelece uma relação de desejo da conquista do outro [ouvinte] e a partir desta conquista o cantor poderá deter a atenção do expectador para a performance. Desse modo, a expressividade estará implicada no grau de comunicação estabelecida entre cantor e público.

0 eixo temático "emoção" apresentou uma tendência a se diferenciar entre homens e mulheres, entre as cinco classificações vocais (principalmente para sopranos) e entre as três faixas etárias (20 a 30; 31 a 40; acima de 40). Os resultados evidenciam dados que corroboram com a opinião de ABDO (2005) no que se refere ao sentimento do cantor durante uma performance. Para a autora quando o cantor interpreta uma personagem carrega em si todo sentimento que lhe é próprio, evidenciando 


\begin{tabular}{|c|c|c|c|c|c|c|c|}
\hline \multirow{3}{*}{\multicolumn{2}{|c|}{$\begin{array}{l}\text { CARACTERIZAÇÃO DOS } \\
\text { SUJEITOS }\end{array}$}} & \multicolumn{6}{|c|}{ EIXOS TEMÁTICOS } \\
\hline & & \multirow{2}{*}{$\begin{array}{c}\text { Técnica } \\
n \\
(\%) \\
\end{array}$} & \multirow{2}{*}{$\begin{array}{c}\text { Emoção } \\
n \\
(\%) \\
\end{array}$} & \multirow{2}{*}{$\begin{array}{c}\text { Corpo } \\
n \\
(\%)\end{array}$} & \multirow{2}{*}{\begin{tabular}{|c|} 
Interpretação \\
$\mathrm{n}$ \\
$(\%)$
\end{tabular}} & \multirow{2}{*}{$\begin{array}{c}\text { Entrega } \\
\mathrm{n} \\
(\%)\end{array}$} & \multirow{2}{*}{\begin{tabular}{|c} 
Habilidades \\
$\mathbf{n}$ \\
$(\%)$
\end{tabular}} \\
\hline & & & & & & & \\
\hline SEXO & $\begin{array}{l}\text { Mulher } \\
\text { Homem }\end{array}$ & $\begin{array}{c}17 \\
(70,83) \\
15 \\
(57,69)\end{array}$ & $\begin{array}{c}21 \\
(87,50) \\
17 \\
(65,38)\end{array}$ & $\begin{array}{c}14 \\
(58,33) \\
10 \\
(40,00)\end{array}$ & $\begin{array}{c}09 \\
(37,50) \\
10 \\
(38,46)\end{array}$ & $\begin{array}{c}11 \\
(45,83) \\
16 \\
(61,54)\end{array}$ & $\begin{array}{c}16 \\
(66,67) \\
13 \\
(50,00)\end{array}$ \\
\hline \multicolumn{2}{|l|}{ Total referido } & 32 & 38 & 24 & 19 & 27 & 29 \\
\hline \multicolumn{2}{|l|}{ Valor de $p$} & 0,333 & 0,067 & 0,752 & 0,944 & 0,266 & 0,233 \\
\hline $\begin{array}{l}\text { CLASS. } \\
\text { VOCAL }\end{array}$ & $\begin{array}{l}\text { Soprano } \\
\text { Mezzo } \\
\text { Tenor } \\
\text { Barítono } \\
\text { Baixo }\end{array}$ & $\begin{array}{c}11 \\
(61,11) \\
06 \\
(100,00) \\
03 \\
(60,00) \\
08 \\
(53,33) \\
04 \\
(66,67)\end{array}$ & $\begin{array}{c}16 \\
(88,89) \\
05 \\
(83,33) \\
04 \\
(80,00) \\
11 \\
(73,33) \\
02 \\
(33,33)\end{array}$ & $\begin{array}{c}09 \\
(50,00) \\
05 \\
(83,33) \\
02 \\
(40,00) \\
06 \\
(40,00) \\
03 \\
(50,00)\end{array}$ & $\begin{array}{c}07 \\
(38,89) \\
02 \\
(33,33) \\
02 \\
(40,00) \\
05 \\
(33,33) \\
03 \\
(50,00)\end{array}$ & $\begin{array}{c}08 \\
(44,44) \\
03 \\
(50,00) \\
02 \\
(40,00) \\
10 \\
(66,67) \\
04 \\
(66,67)\end{array}$ & $\begin{array}{c}18 \\
(72,22) \\
06 \\
(50,00) \\
03 \\
(60,00) \\
09 \\
(60,00) \\
04 \\
(66,67)\end{array}$ \\
\hline \multicolumn{2}{|l|}{$\begin{array}{l}\text { Total referido } \\
\text { Valor de } p\end{array}$} & $\begin{array}{c}32 \\
0,375\end{array}$ & $\begin{array}{c}38 \\
0,095\end{array}$ & $\begin{array}{c}24 \\
0,407\end{array}$ & $\begin{array}{c}19 \\
0,966\end{array}$ & $\begin{array}{c}27 \\
0,653 \\
\end{array}$ & $\begin{array}{c}29 \\
0,428\end{array}$ \\
\hline FORMAÇÃO & $\begin{array}{l}\text { Informal } \\
\text { Graduação }\end{array}$ & $\begin{array}{c}11 \\
(64,71) \\
21 \\
(63,64)\end{array}$ & $\begin{array}{c}15 \\
(88,24) \\
23 \\
(69,70)\end{array}$ & $\begin{array}{c}09 \\
(52,94) \\
16 \\
(48,48)\end{array}$ & $\begin{array}{c}07 \\
(41,18) \\
12 \\
(36,36)\end{array}$ & $\begin{array}{c}06 \\
(35,29) \\
21 \\
(63,64)\end{array}$ & $\begin{array}{c}08 \\
(47,06) \\
21 \\
(63,64)\end{array}$ \\
\hline \multicolumn{2}{|l|}{ Total referido } & 32 & 38 & 24 & 19 & 27 & 29 \\
\hline \multicolumn{2}{|l|}{ Valor de $p$} & 0,941 & 0,146 & 0,765 & 0,740 & 0,057 & 0,261 \\
\hline $\begin{array}{l}\text { TEMPO DE } \\
\text { ATIVIDADE }\end{array}$ & $\begin{array}{l}03 \text { a } 10 \\
11 \text { a } 20 \\
\text { Acima } 21\end{array}$ & $\begin{array}{c}11 \\
(73,33) \\
14 \\
(63,64) \\
07 \\
(53,85)\end{array}$ & $\begin{array}{c}09 \\
(60,00) \\
17 \\
(77,27) \\
12 \\
(92,31)\end{array}$ & $\begin{array}{c}08 \\
(53,33) \\
11 \\
(52,38) \\
05 \\
(38,46)\end{array}$ & $\begin{array}{c}07 \\
(47,67) \\
08 \\
(36,36) \\
04 \\
(30,77)\end{array}$ & $\begin{array}{c}02 \\
(13,33) \\
16 \\
(72,73) \\
09 \\
(69,23)\end{array}$ & $\begin{array}{c}09 \\
(60,00) \\
13 \\
(59,09) \\
07 \\
(53,85)\end{array}$ \\
\hline \multicolumn{2}{|l|}{ Total referido } & 32 & 38 & 24 & 19 & 27 & 29 \\
\hline \multicolumn{2}{|l|}{ Valor de $p$} & 0,563 & 0,134 & 0,675 & 0,673 & 0,001 & 0,938 \\
\hline $\begin{array}{l}\text { FAIXA } \\
\text { ETÁRIA }\end{array}$ & $\begin{array}{l}20 \text { a } 30 \\
31 \text { a } 40 \\
\text { Acima } 41\end{array}$ & $\begin{array}{c}10 \\
(83,33) \\
07 \\
(53,85) \\
15 \\
(60,00)\end{array}$ & $\begin{array}{c}06 \\
(50,00) \\
11 \\
(84,00) \\
21 \\
(84,00)\end{array}$ & $\begin{array}{c}07 \\
(63,63) \\
06 \\
(50,00) \\
07 \\
(41,18)\end{array}$ & $\begin{array}{c}03 \\
(25,00) \\
07 \\
(53,85) \\
09 \\
(36,00)\end{array}$ & $\begin{array}{c}04 \\
(33,33) \\
07 \\
(53,85) \\
16 \\
(64,00)\end{array}$ & $\begin{array}{c}07 \\
(58,33) \\
06 \\
(46,15) \\
16 \\
(64,00)\end{array}$ \\
\hline \multicolumn{2}{|l|}{ Total referido } & 32 & 38 & 20 & 24 & 27 & 29 \\
\hline Valor de $\mathrm{p}$ & & 0,259 & 0,054 & 0,510 & 0,757 & 0,215 & 0,572 \\
\hline
\end{tabular}

Correlação de Pearson: $p \leq 0,05$

Ex.2 - Correlação entre os eixos temáticos sobre expressividade e caracterização dos sujeitos segundo sexo, classificação vocal, formação, tempo de atividade e faixa etária.

dessa forma uma característica própria de interpretar. Portanto, no cruzamento do eixo temático "emoção" com o eixo temático "sexo" o valor de $p=0,067$, representa que a emoção na performance do cantor é um dado mais importante na opinião das mulheres $(21=87,5 \%)$ do que dos homens $(17=65,38 \%)$. Esse resultado está reforçado na correlação entre as classificações vocais e a emoção, isto porque pode-se observar que entre as mulheres há diferença entre a porcentagem de sopranos $(88,89 \%)$ e as mezzo-sopranos (83,33\%).
No cruzamento do eixo temático "emoção" com "faixa etária" evidenciou-se uma tendência $(p=0,054)$ a afirmar que quanto mais velho for o cantor (a), maior a possibilidade da emoção se tornar importante para a expressividade durante a performance. Cabe ressaltar que segundo alguns autores (SALGAD0, 2001; PAULA e BORGES, 2004; MAULÉON e MARTINEZ, 2004), a emoção deve fazer parte de toda performance, porem é necessário um estado de controle, para que as reações inerentes a ela não interfiram na capacidade do cantor em estabelecer 
uma relação com a plateia. Ou seja, a emoção não pode interferir de forma negativa no controle vocal e na incorporação do personagem.

Observa-se que nos eixos temáticos: técnica, corpo, interpretação e habilidade não há diferença estatisticamente significante, portanto, presume-se que há um entendimento homogêneo entre os cantores. Porém, não se pode afirmar que estes eixos sejam importantes para todos os cantores, pois os eixos foram baseados na opinião da maioria.

Em relação às habilidades de cada intérprete, deve-se estar atento à estreita relação que existe entre o potencial técnico de cada cantor com o momento e a intenção interpretativa durante uma performance, estes atributos configuram a singularidade da espontaneidade do cantor quando está em cena. Sobre este aspecto, HIGUCHI e LEITE (2007) consideram que a espontaneidade é um elemento facilitador da expressividade interpretativa musical, portanto, a restrição na performance pode ocasionar inibição na expressividade. Em contrapartida, a total espontaneidade conduz a uma real limitação na capacidade expressiva.

SHIFRES (2001) criou um neologismo metafórico, "metatexto", referindo-se, provavelmente, à palavra metalinguagem, que significa linguagem que se utiliza para descrever outra linguagem ou qualquer sistema de significação. Para o autor, a execução musical é um processo complexo de reconstrução em que o texto interpretado e a partitura revelam-se em outro texto, ou seja, a execução é compreendida como um "metatexto", que traz uma oportunidade de estudo sobre as tensões entre as intenzioni [intenções] de cada intérprete. De acordo com MAULÉON e MARTINEZ (2004), a música e os processos de comunicação envolvidos em sua produção vinculam-se a processos corporais e neurológicos. Esses mecanismos são compartilhados entre o intérprete e o ouvinte e permitem o acesso em tempo real à informação contida no sinal sonoro, por conseguinte possibilita uma compreensão do discurso, de natureza expressiva e emocional, de forma não consciente.

0 eixo temático "corpo" corrobora com a opinião de PAULA e BORGES, (2004). Segundo os autores, durante uma performance, a própria apresentação pública é o agente estressor. Tal estado tem aspectos positivos, pois prepara o corpo para responder mais prontamente à situação que se configura. Assim, o coração com batimentos acelerados, suor frio, respiração intensificada, frio no estômago e outras, são sensações ativadas pela mente com o objetivo de preparar o corpo para a ação e cabe ao intérprete controlar-se emocionalmente, por meio de uma postura mental adequada. Desse modo, a qualidade da performance depende tanto da capacidade de execução, quanto do autocontrole diante do público.

\section{5- Considerações finais}

Os resultados desta pesquisa demonstraram haver homogeneidade na opinião dos cantores líricos participantes que, quando solicitado que citassem palavras relacionadas à expressividade, fizeram referências a seis eixos temáticos, a saber: emoção, técnica, habilidades, entrega, corpo e interpretação. Quando esses eixos foram relacionados às características pessoais dos cantores, pôde-se inferir que a expressividade do cantor lírico diz respeito à emoção, à capacidade de entrega ao personagem e ao público, e isso se conquista com anos de experiências na profissão.

\section{Referências}

ABDO, Sandra N. Sobre o problema da autonomia da arte e suas implicações hermenêuticas e ontológicas. Kriterion [online], 2005, v. 46, n.112, p.357-366.

ANDRADA E SILVA, Marta A. Expressividade no canto. In: KYRILLOS Leny R., organizadora. Expressividade: da teoria ḋ prática. São Paulo: Revinter, 2005, p.91-103.

CAVAZOTI, André. Caminhos para pesquisa na área de performance musical: uma breve introdução à fenomenologia da música. Cadernos do Instituto de Artes da UNICAMP, Campinas, 2001, v.5, p.35-38.

COSTA, Patrícia. A expressão cênica como elemento facilitador da performance no coro juvenil. Per Musi, 2009, n.19, p.63-71.

GABRIELSSON AIf, JUSLIN Patrick N. Emotional Expression in Music Performance: Between the Performer's Intention and the Listener's Experience. Psychology of Music, 1996, n.24, p.68-91,

HIGUCHI Marcia K.K. Fidelidade ao texto e a expressividade na interpretação musical: uma visão neuropsicológica. Anais do SIMCAM4 - IV Simpósio de Cognição e Artes Musicais, 2008. Disponível em: http://www.fflch.usp.br/dl/simcam4/ downloads_anais/SIMCAM4_Marcia_Higuchi.pdf

HIGUCHI, Marcia K.K, LEITE João P. Rigidez métrica e expressividade na interpretação musical: uma teoria neuropsicológica. Opus: Rev. da Associação Nacional de pesquisa e pós-graduação em música - ANPPOM (Goiânia), 2007, n.13, v.2, p.187-207. Disponível em: <http://www.anppom.com.br/opus/opus13/212/12-Higuchi-Leite.htm 
LOUREIRO, Mauricio A. A pesquisa empírica em expressividade musical: métodos e modelos de representação e extração de informação de conteúdo expressivo musical. Rev. Opus, 2006, n.12, v.12, p.1-26. Disponível em: http://www. anppom.com.br/opus/opus12/01_Mauricio.pdf

MAULÉON Claudia, MARTINEZ Isabel C. Co-articulacion em el canto: uma clave para analisis del discurso expressivo. Anais IV Reunion de SACCOM, 2004. Disponivel em: http://www.saccom.org.ar/2004_reunion4/actas_indice.htm

MINAYO, Maria Cecília de S. 0 desafio do conhecimento: pesquisa qualitativa em saúde. $8^{\circ}$ Ed. São Paulo: Hucitec. (2004).

MUSZKAT Mauro, CORREIA Cléo MF, CAMPOS Sandra M. Música e Neurociências. Rev. Neurociências, 2000, n. 8, v.2, p.70-75.

PAREYSON Luigi. Os problemas da estética. $3^{a}$ ed. São Paulo: Martins Fontes, 1997, 246p.

PAULA L, Lucia; BORGES Maria Helena J. 0 ensino da performance musical: uma abordagem teórica sobre o desenvolvimento dos eventos mentais relacionados às ações e emoções presentes no fazer musical. Música Hodie, 2004, n.4, v.1.p.29-44.

SCHENKER Heinrich. The Art of Performance. New York: Oxford University Press; 2000.

SALGADO Antônio G. A expressividade na face e na voz do cantor e sua importância na comunicação do conteúdo emotivo de uma performance musical. Performance - Revista de Interpretação Musical, 2006, n.2, p.1-13. Disponível em: <http://www.performanceonline.org/pt/edicoes/pt/n2/SalgadoPrt.pdf >

Contributo para a Compreensão de Alguns dos Processos Perceptivos e Cognitivos Implicados no Reconhecimento da Expressão da Emoção Facial e Vocal no Canto. In: Actas della Primera Reunión Anual de SACCoM. Avellaneda: Ed. Flavio Shifres, 2001. Disponivel em: <http://www.saccom.org.ar/secciones/primera/Papers/Salgado/Salgado.htm

SAPOLSKY Robert. Assumindo o controle do estresse. Rev. Scientific American Brasil, 2003, n.17, v.1, p.79-87.

SHIFRES Flavio. El ejecutante como intérprete: un estudio acerca de la cooperación interpretativa del ejecutante en la obra musical In: Actas della Primera Reunión Anual de SACCOM. Ed. Flavio Shifres. Avellaneda. Universidad de Buenos Aires, 2001. Disponivel: http://www.saccom.org.ar/secciones/primera/Papers/Shifres/Shifres.htm

Enio Lopes Mello é cantor lírico e terapeuta corporal, especializado no método de Cadeias musculares e articulares GDS ICTGDS-Bruxelas, Mestre em Fonoaudiologia pela Pontifícia Universidade Católica de São Paulo e Doutorando em Fonoaudiologia pela Pontifícia Universidade Católica de São Paulo. Tenor solista do Coral Tanus da Cidade de São Paulo. Membro do Laboratório de Voz da PUCSP (LABORVOX/PUCSP)

Léslie Piccolotto Ferreira é Fonoaudióloga. Mestre em Linguistica Aplicada ao Ensino de Línguas pela Pontifícia Universidade Católica de São Paulo e doutora em Distúrbios da Comunicação Humana (Fonoaudiologia) pela Universidade Federal de São Paulo. Professora e coordenadora do Programa de estudos pós-graduados em Fonoaudiologia da PUCSP. Diretora do LABORVOX/PUCSP.

Natalia Fonseca Pacheco é cantora lírica; Bacharel em Musica pela Universidade do Estado de Minas Gerais; Mestre em Fonoaudiologia pela Pontifícia Universidade Católica de São Paulo. Cantora efetiva do Coral Lírico de Minas Gerais (Palácio das Artes). Membro do LABORVOX/PUCSP.

Marta Assumpção de Andrada e Silva é fonoaudióloga clinica, Mestre em Distúrbios da Comunicação pela Pontifícia Universidade Católica de São Paulo, Doutora em Comunicação e Semiótica pela Pontifícia Universidade Católica de São Paulo. Professora Assistente Doutora na Pós-graduação e Graduação em Fonoaudiologia da Pontifícia Universidade Católica de São Paulo; Professora Adjunta no Curso de Fonoaudiologia da Faculdade de Ciências Médicas da Santa Casa de Misericórdia de São Paulo. Membro do LABORVOX/PUCSP. 